\title{
Resveratrol protects late endothelial progenitor cells from TNF- $\alpha$-induced inflammatory damage by upregulating Krüppel-like factor-2
}

\author{
HAIRONG CHU* , HONG LI* , XIUMEI GUAN, HONG YAN, XIAOYUN ZHANG, \\ XIAODONG CUI, XIN LI and MIN CHENG
}

Clinical Medical College, Weifang Medical University, Weifang, Shandong 261053, P.R. China

Received August 21, 2017; Accepted January 3, 2018

DOI: $10.3892 / \mathrm{mmr} .2018 .8621$

\begin{abstract}
Cardiovascular risk factors can negatively influence late endothelial progenitor cell (EPCs) number and functions, thus EPCs biology is a clinical implications for cardiovascular diseases. The present study aimed to investigate the potential protective effects of resveratrol (RES) on tumor necrosis factor (TNF)- $\alpha$-induced inflammatory damage in late endothelial progenitor cells (EPCs) and to elucidate the underlying mechanisms. Late EPCs at passages 3-5 were pretreated with RES at a concentration of $20 \mu \mathrm{mol} / 1$ for $12 \mathrm{~h}$ and subsequently incubated with TNF- $\alpha$ (10 $\mathrm{ng} / \mathrm{ml})$ for $24 \mathrm{~h}$. The adhesion, migration, proliferation and vasculogenesis of EPCs were subsequently detected. Furthermore, the mRNA expression levels of intercellular adhesion molecule-1 (ICAM-1) and monocyte chemoattractant protein-1 (MCP-1) were measured by reverse transcription-quantitative polymerase chain reaction (RT-qPCR). Nitric oxide (NO) levels in the supernatant were determined using a colorimetric assay kit. Additionally, the mRNA and protein expression of Krüppel-like factor-2 (KLF2) was determined by RT-qPCR and western blot analysis, respectively. The results indicated that TNF- $\alpha$ markedly inhibited the proliferation, adhesion, migration and vasculogenesis of late EPCs. However, RES ameliorated the effects induced by TNF- $\alpha$. Furthermore, exposure of EPCs to TNF- $\alpha$ decreased the levels of NO secretion and KLF2 expression at the mRNA and protein levels, but upregulated the levels of inflammatory factors, including ICAM-1 and MCP-1, compared with the control group. RES significantly inhibited TNF- $\alpha$-induced inflammatory damage through upregulation
\end{abstract}

Correspondence to: Professor Min Cheng, Clinical Medical College, Weifang Medical University, 7166 Baotongxi Road, Weifang, Shandong 261053, P.R. China

E-mail: mincheng@wfmc.edu.cn

*Contributed equally

Key words: late endothelial progenitor cells, resveratrol, tumor necrosis factor- $\alpha$, Krüppel-like factor-2 of KLF2 expression and downregulation of the expression of ICAM-1 and MCP-1. In conclusion, RES may exert protective effects on the cardiovascular system, as demonstrated by the amelioration of TNF- $\alpha$-induced inflammation in EPCs following RES treatment, and may therefore be used in the future for the prevention of cardiovascular disease.

\section{Introduction}

Cardiovascular risk factors promote the development of atherosclerosis (AS) by inducing endothelial cell injury and dysfunction; therefore, improving endothelial function may limit AS (1). An increasing amount of evidence indicates that endothelial progenitor cells (EPCs) function in endogenous endothelial regeneration and repair of damaged endothelium (2-4). In addition, inflammation is associated with atherosclerotic disease (5) and inflammatory mechanisms may contribute to EPC impairment in AS (6). Therefore, drugs protecting EPCs from inflammatory damage may have potential in the treatment of AS.

Trans-3,4',5-trihydroxystilbene, also termed resveratrol (RES), is a natural polyphenol compound that is present in grapes, red wine and other food products (7). Previous studies have reported that RES induces a protective effect on the cardiovascular system (8-10). It has been demonstrated that elevated levels of tumor necrosis factor (TNF)- $\alpha$ in the blood are associated with AS (11) and that RES restores endothelial function in diabetes by suppressing TNF- $\alpha$-induced upregulation of NADPH oxidase and promoting the phosphorylation of endothelial nitric oxide (NO) synthase (eNOS) (12). However, the direct effects and the underlying mechanisms of RES in AS are yet to be elucidated.

Krüppel-like factors (KLFs) belong to a family of transcription factors that are responsible for various biological processes, including proliferation, development and apoptosis (13). Among the members of the KLF family, KLF2 functions in several signaling pathways associated with cell migration, vasomotor function and hemostasis (14-16). Previous studies have demonstrated that KLF2 regulates endothelial thrombotic function and the expression of flow-responsive genes induced by shear stress $(14,17)$. However, the expression of KLF2 is inhibited by TNF- $\alpha$ (18) and it remains to be determined 
whether RES is able to inhibit TNF- $\alpha$-induced inflammatory damage in late EPCs via regulation of KLF2 functional pathways. The present study aimed to determine the effects of RES on the functions of late EPCs and the underlying mechanism of TNF- $\alpha$-induced inflammatory damage in late EPCs.

\section{Materials and methods}

Identification and culture of EPCs. Late EPCs were cultured in vitro, as previously described (19). Initially, bone marrow was separated from one male and one female Sprague-Dawley rats (150 to 175 g, 8 weeks; Weifang Medical College, Weifang, China), which were housed under controlled conditions (12-h light/dark cycle, $22^{\circ} \mathrm{C}, 60 \%$ humidity) with ad libitum access to food and water and mononuclear cells were separated by density gradient centrifugation under $4^{\circ} \mathrm{C}(700 \mathrm{x} \mathrm{g}$ for $20 \mathrm{~min})$ with Histopaque ${ }^{\circledR}-1083$ (Sigma-Aldrich; Merck KGaA, Darmstadt, Germany). Subsequently, mononuclear cells were inoculated on dishes precoated with $5 \%$ fibronectin (Sigma-Aldrich; Merck KGaA,) and cultured in complete Endothelial Cell Growth Medium-2 (CC-3202; Lonza Group, Ltd., Basel, Switzerland) at $37^{\circ} \mathrm{C}$ and $5 \% \mathrm{CO}_{2}$ in a humidified atmosphere for 4 days. Subsequently, non-adherent cells were washed away with PBS. The culture was maintained for an additional 7 days, during which the medium was replaced every other day. EPC identification was performed as described in our previous study (19) and EPCs at passages 3-5, considered late EPCs, and $2 \times 10^{6} \mathrm{EPCs} /$ well were seeded in 6-well plates and used for subsequent experiments (20).

Late EPC cells were divided into three groups with different treatments: TNF- $\alpha$ group, EPCs were cultured with TNF- $\alpha$ (10 ng/ml; PeproTech, Inc., Rocky Hill, NJ, USA) at $37^{\circ} \mathrm{C}$ for $24 \mathrm{~h}$; RES + TNF- $\alpha$ group, EPCs were cultured with RES $\left(20 \mu \mathrm{mol} / 1\right.$; Sigma-Aldrich; Merck KGaA) at $37^{\circ} \mathrm{C}$ for $12 \mathrm{~h}$ prior to treatment with TNF- $\alpha(10 \mathrm{ng} / \mathrm{ml})$ at $37^{\circ} \mathrm{C}$ for $24 \mathrm{~h}$; and dimethyl sulfoxide (DMSO) group, EPCs were treated with the same volume of DMSO at $37^{\circ} \mathrm{C}$ for $24 \mathrm{~h}$. The present study was approved by the Medical Ethics Committee of Weifang Medical University (Weifang, China) and was performed in accordance with the committee guidelines.

Cell proliferation assays. Late EPCs at the density of 10,000 cells/well were seeded in triplicate in 96-well plates. Cell proliferation ability was detected using a Cell-Light ${ }^{\mathrm{TM}}$ 5-ethynyl-2'-deoxyuridine (EdU) DNA Cell Proliferation kit (Guangzhou RiboBio Co., Ltd., Guangzhou, China) according to the manufacturer's protocol. Results of the proliferation assay were observed under Apollo ${ }^{\circledR} 567$ reaction reagent at room temperature for $30 \mathrm{~min}$ in dark and counterstained with DAPI at room temperature for $15 \mathrm{~min}$ and images from five random fields/well were captured at x200 magnification. Image-Pro Plus 6.0 software (Media Cybernetics, Inc., Rockville, MD, USA) was used to calculate the percentage of EdU-positive cells of all cells.

EPC migration assay. Migration of late EPCs was measured using a modified Boyden chamber assay, as previously described (19). Briefly, following pretreatment with $20 \mu \mathrm{mol} / \mathrm{l}$ RES for $12 \mathrm{~h}$, EPCs were cultured with TNF- $\alpha(10 \mathrm{ng} / \mathrm{ml})$ for another $24 \mathrm{~h}$ in a serum-free EGM2 medium. A total of
$4 \times 10^{4}$ EPCs were added in the upper insert of the chamber in an EGM2 medium (Lonza Group, Ltd.,) and also EGM2 medium with fetal bovine serum was added to the bottom chamber. Following incubation for $8 \mathrm{~h}$ at $37^{\circ} \mathrm{C}$ in an incubator with $5 \% \mathrm{CO}_{2}$, the membrane in the upper chamber was washed gently with PBS and non-migratory cells were scraped using cotton swabs. Subsequently, EPCs were fixed with $4 \%$ paraformaldehyde at room temperature for $30 \mathrm{~min}$ and stained with DAPI at room temperature for $15 \mathrm{~min}$, and the number of migratory cells in the bottom chamber in six randomly selected fields/well was calculated under a fluorescent microscope (Leica Microsystems GmbH, Wetzlar, Germany; DMI 4000; magnification, $\mathrm{x} 100)$.

EPC adhesion assay. The adhesion assay was performed as previously described (21). Following pretreatment with $20 \mu \mathrm{mol} / 1 \mathrm{RES}$ for $12 \mathrm{~h}$, EPCs were stimulated with $10 \mathrm{ng} / \mathrm{ml}$ TNF- $\alpha$ for $24 \mathrm{~h}$. Subsequently, EPCs $\left(1 \times 10^{4}\right)$ were placed onto fibronectin-coated 12 -well plates and incubated at $37^{\circ} \mathrm{C}$ for $30 \mathrm{~min}$. Following washing of non-adherent cells with PBS, the adherent cells were counted independently in six random fields/well under an inverted phase contrast microscope (Leica Microsystems GmbH; DM 1400B; magnification, x100).

Tube formation assay. The tube formation ability of EPCs on Matrigel (BD Biosciences, San Jose, CA, USA) was detected. Initially, a 96-well plate precoated with $100 \mu \mathrm{l}$ Matrigel at $37^{\circ} \mathrm{C}$ for $1 \mathrm{~h}$ was prepared. Subsequently, $100 \mu \mathrm{l}$ late EPCs $\left(2 \times 10^{4}\right.$ cells $\left./ \mathrm{ml}\right)$ were seeded into each well and incubated for $6 \mathrm{~h}$ at $37^{\circ} \mathrm{C}$. Images of enclosed networks of tubes were captured in six randomly selected fields under an inverted phase contrast microscope (Leica Microsystems $\mathrm{GmbH}$; DM 1400B; magnification, x200) and the length of complete tubes formed/unit area was quantified by Image-Pro Plus 6.0 software (Media Cybernetics, Inc.).

Quantification of NO. The total amount of NO in the culture supernatant of EPCs from three groups were, respectively measured using a Nitric Oxide (NO) assay kit (cat. no. A012-1; Nanjing Jiancheng Bioengineering Institute, Nanjing, China) based on the Griess reaction. The total nitrite level was measured to assess NO levels at $550 \mathrm{~nm}$ according to the manufacturer's protocol. As NO is easily transformed to nitrite and nitrate in vivo, therefore the total nitrite and nitrate level may represent the NO level. In the presence of nitrate reductase in the kit that was used, nitrate is reduced to nitrite via reduced NADPH and then nitrite level was examined by the colorimetric assay kit.

Reverse transcription-quantitative polymerase chain reaction (RT-qPCR) analysis. Total RNA was extracted using TRIzol reagent (Invitrogen; Thermo Fisher Scientific, Inc., Waltham, MA, USA) and PrimeScript ${ }^{\mathrm{TM}}$ RT Master Mix (RR036A; Takara Biotechnology Co., Ltd., Dalian, China) was used to synthesize cDNA at $37^{\circ} \mathrm{C}$ for $15 \mathrm{~min}$. Subsequently, qPCR was performed using SYBR Premix Ex Taq ${ }^{\mathrm{TM}}$ (RR420A; Takara Biotechnology Co., Ltd.) using the synthesized cDNA as a template. The thermal cycling conditions were as follows: $30 \mathrm{sec}$ at $95^{\circ} \mathrm{C}$ for pre-denaturation, 40 cycles for $15 \mathrm{sec}$ at $95^{\circ} \mathrm{C}$ for denaturation, $1 \mathrm{~min}$ at $59^{\circ} \mathrm{C}$ for annealing, and $10 \mathrm{sec}$ 

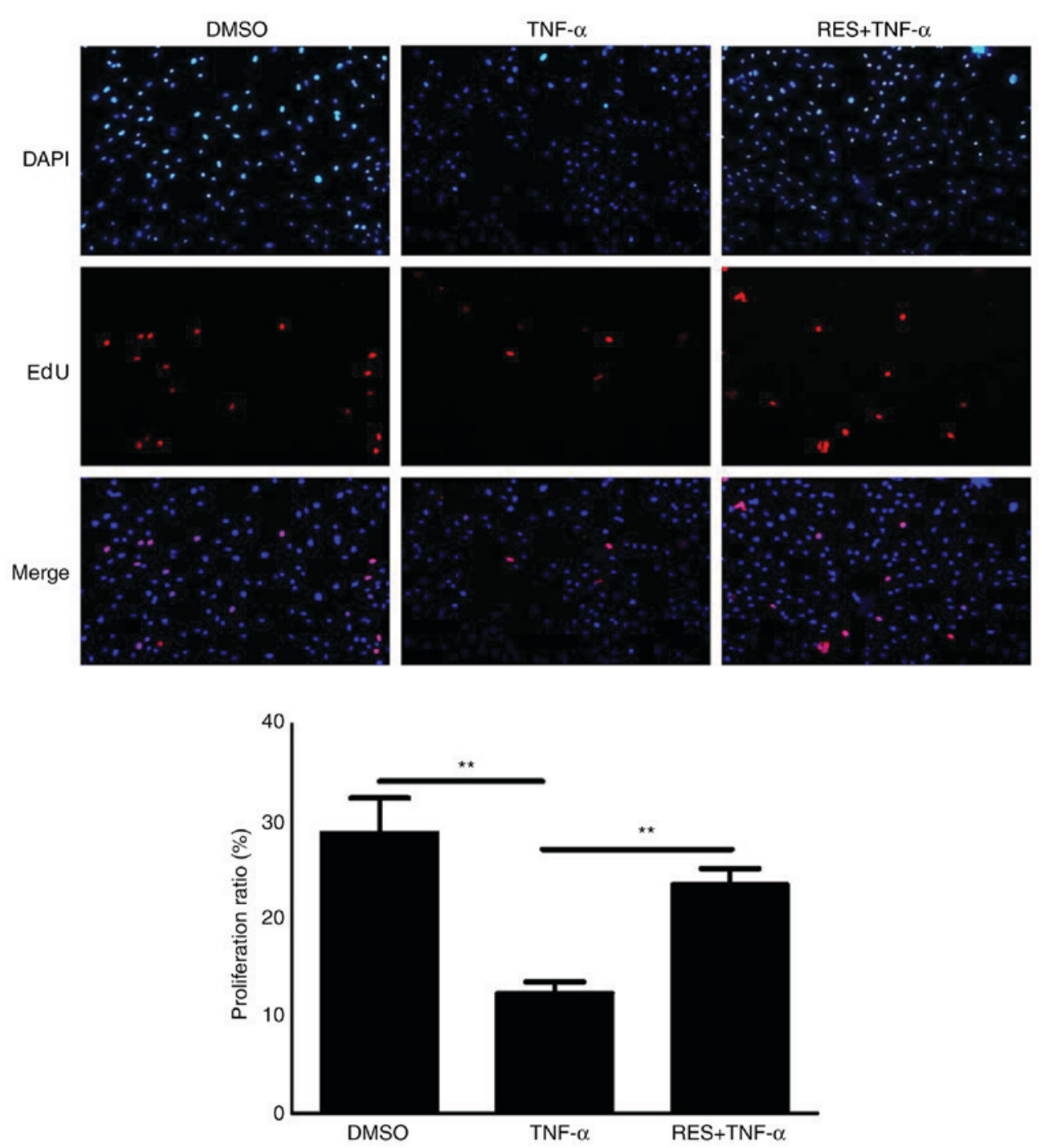

Figure 1. Effect of RES on the viability of EPCs treated with TNF- $\alpha$ as determined using an EdU assay. Images from five random fields per well were captured at x200 magnification. Treatment with TNF- $\alpha$ decreased the proliferation of EPCs, which was restored by co-culture with TNF- $\alpha$ and RES. EPCs treated with DMSO only served as the blank group. Data are presented as the mean + standard error of the mean, $\mathrm{n}=5 .{ }^{* *} \mathrm{P}<0.01$, as indicated. RES, resveratrol; EPCs, endothelial progenitor cells; TNF- $\alpha$, tumor necrosis factor- $\alpha$; EdU, 5-ethynyl-2'-deoxyuridine; DMSO, dimethyl sulfoxide.

at $80^{\circ} \mathrm{C}$ for elongation. The following gene-specific oligonucleotide sequences were used: GAPDH, 5'-GGCACAGTCAAG GCTGAGAATG-3' (forward) and 5'-ATGGTGGTGAAG ACGCCAGTA-3' (reverse); KLF2, 5'-TCGCACCTAAAG GCGCATC-3' (forward) and 5'-TAGTGGCGGGTAAGCTCG TC-3' (reverse); monocyte chemoattractant protein-1 (MCP-1), 5'-CTATGCAGGTCTCTGTCACGCTTC-3' (forward) and 5'-CAGCCGACTCATTGGGATCA-3' (reverse); and intercellular adhesion molecule-1 (ICAM-1), 5'-GCTTCTGCC ACCATCACTGTGTA-3' (forward) and 5'-ATGAGGTTC TTGCCCACCTG-3' (reverse). RT-qPCR was performed using a LightCycler 480 Instrument II (Roche Diagnostics $\mathrm{GmbH}$, Mannheim, Germany). Amplification of GAPDH was performed as a control for normalization. Fold changes in gene expression were calculated using $2^{-\Delta \Delta C q}$ method (22).

Western blotting. Late EPC cells were divided into six groups with different treatments: TNF- $\alpha$ group, DMSO group, 5 RES $(\mathrm{R})+\mathrm{TNF}-\alpha(\mathrm{T})$ group, $10 \mathrm{R}+\mathrm{T}$ group, $20 \mathrm{R}+\mathrm{T}$ group and $50 \mathrm{R}+\mathrm{T}$ group. The density of EPCs in those six groups was
$2 \times 10^{6}$ cell/well. In $5 \mathrm{R}+\mathrm{T}, 10 \mathrm{R}+\mathrm{T}, 20 \mathrm{R}+\mathrm{T}$ and $50 \mathrm{R}+\mathrm{T}$ groups, EPCs were pretreated with 5, 10, 20, and $50 \mu \mathrm{mol} / 1$ RES at $37^{\circ} \mathrm{C}$ for $12 \mathrm{~h}$, respectively, and then cultured with TNF- $\alpha(10 \mathrm{ng} / \mathrm{ml})$ at $37^{\circ} \mathrm{C}$ for $24 \mathrm{~h}$. In TNF- $\alpha$ and DMSO group, EPCs were cultured with $10 \mathrm{ng} / \mathrm{ml}$ TNF- $\alpha$ or the same volume of DMSO at $37^{\circ} \mathrm{C}$ for $24 \mathrm{~h}$, respectively.

Following the various treatments, late EPCs were lysed using radioimmunoprecipitation assay lysis Solution Enhanced (C1053; Applygen Technologies Inc., Beijing, China) and the lysates were isolated by centrifugation at $12,000 \mathrm{xg}$ and $4^{\circ} \mathrm{C}$ for $5 \mathrm{~min}$. The proteins concentration were determined by bicinchoninic acid (BCA) method (Pierce ${ }^{\mathrm{TM}}$ BCA Protein Assay kit, Thermo Fisher Scientific, Inc.). Then, total proteins with equal quality (40 $\mu \mathrm{g} / \mathrm{lane})$ from each group were separated by $12 \%$ (weight/volume) polyacrylamide gels. Prior to incubation with the primary antibody against KLF2 (cat. no. SAB2108684; 1:500; Sigma-Aldrich; Merck KGaA) overnight at $4^{\circ} \mathrm{C}$, the separated proteins were transferred to polyvinylidene fluoride membranes and non-specific binding proteins were blocked with 5\% bovine serum albumin (cat. no. ST-023; Beyotime 

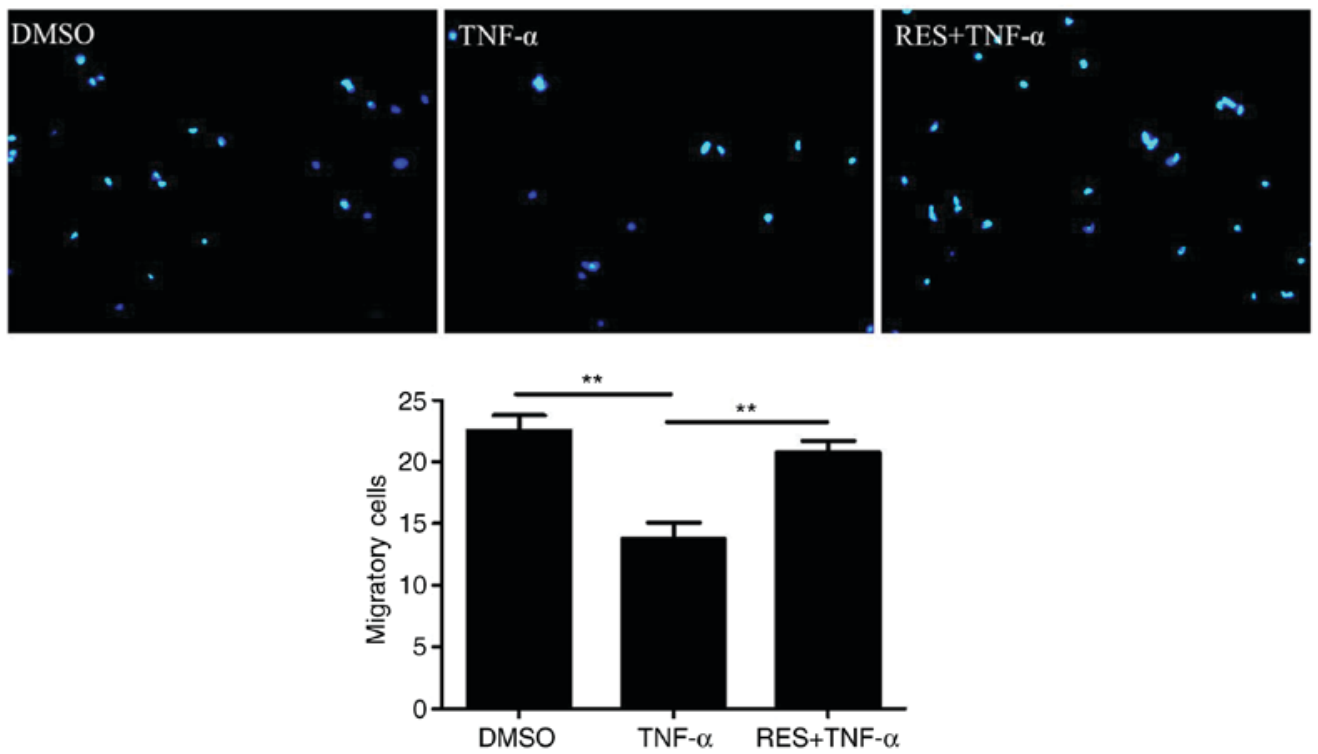

Figure 2. Effect of RES on the migration of late EPCs treated with TNF- $\alpha$. The migration ability of late EPCs was detected by a modified Boyden chamber assay. Migratory cells were counted in six randomly selected high-power microscope fields/well (magnification, x100). Migration capacity of EPCs was inhibited by TNF- $\alpha(10 \mathrm{ng} / \mathrm{ml})$, while it was restored by RES $(20 \mu \mathrm{mol} / \mathrm{l})$. EPCs treated with DMSO only served as the blank group. Data are presented as the mean + standard error of the mean, $\mathrm{n}=5 .{ }^{* * *} \mathrm{P}<0.01$, as indicated. RES, resveratrol; EPCs, endothelial progenitor cells; TNF- $\alpha$, tumor necrosis factor- $\alpha$; DMSO, dimethyl sulfoxide.

Institute of Biotechnology, Jiangsu, China)/0.01 mol/1 TBS-Tween-20 (TBST) for $60 \mathrm{~min}$ at room temperature. $\beta$-actin (cat. no. AF0003; 1:1,000; Beyotime Institute of Biotechnology) was selected as the control and incubated overnight at $4^{\circ} \mathrm{C}$. Subsequently, membranes were washed with TBST and incubated with horseradish peroxidase-conjugated secondary antibody (cat. no. SC-2357; 1:1,000; Santa Cruz Biotechnology, Inc., Dallas, TX, USA) at room temperature for $60 \mathrm{~min}$. Immunoreactive bands were visualized by Amersham enhanced chemiluminescence (ECL) western blotting detection reagent (GE Healthcare Life Sciences, Little Chalfont, UK). Finally, a densitometric analysis for the western blot was performed by GelPro Analyser 4.0 software (Media Cybernetics, Inc., Rockville, MD, USA).

Statistical analysis. Data are presented as the mean \pm standard error of the mean. Statistical analysis was performed by one-way analysis of variance and Tukey-Kramer post-hoc test was applied for multiple comparisons. All the experiments were repeated three times. All statistical analyses were performed using SPSS 16.0 software (SPSS, Inc., Chicago, IL, USA). $\mathrm{P}<0.05$ was considered to indicate a statistically significant difference.

\section{Results}

Effects of RES on viability of EPCs treated with TNF- $\alpha$. Based on the results of the EdU assay, the proliferative potential of EPCs treated with TNF- $\alpha(10 \mathrm{ng} / \mathrm{ml})$ was markedly reduced compared with the DMSO group $(\mathrm{P}<0.01$; Fig. 1). However, cell viability in the RES + TNF- $\alpha$ group was significantly increased compared with the TNF- $\alpha$ group $(\mathrm{P}<0.01$; Fig. 1).

Effects of RES on the migration of EPCs. To determine the effect of RES on the migration of EPCs, a migration assay was

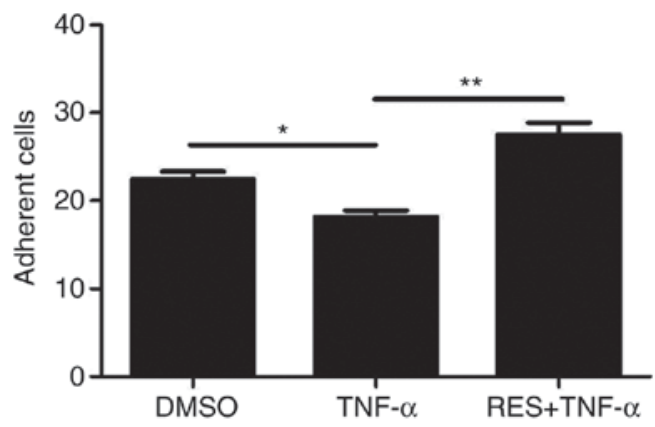

Figure 3. Effect of RES on the adhesion of late EPCs that was impaired by TNF- $\alpha$ in vitro. The adhesion capacity of late EPCs was decreased by TNF- $\alpha(10 \mathrm{ng} / \mathrm{ml})$, while RES $(20 \mu \mathrm{mol} / \mathrm{l})$ increased the adhesion ability of late EPCs. EPCs treated with DMSO only served as the blank group. Data are presented as the mean + standard error of the mean, $n=5$. ${ }^{*} \mathrm{P}<0.05$ and ${ }^{* * *} \mathrm{P}<0.01$, as indicated. RES, resveratrol; EPCs, endothelial progenitor cells; TNF- $\alpha$, tumor necrosis factor- $\alpha$; DMSO, dimethyl sulfoxide.

conducted. The results indicated that TNF- $\alpha$ markedly inhibited the migration of EPCs (TNF- $\alpha$ group vs. DMSO group, $13.75 \pm 2.63$ vs. $22.5 \pm 2.52$ cells/high-power field, respectively; $\mathrm{P}<0.01$; Fig. 2). However, RES significantly enhanced the migration ability of EPCs in TNF- $\alpha$-treated cells; the number of migratory EPCs in the RES + TNF- $\alpha$ group was markedly increased compared with the TNF- $\alpha$ group $(20.75 \pm 1.89$ vs. $13.75 \pm 2.63$ cells/high-power field, respectively; $\mathrm{P}<0.01$; Fig. 2).

RES improves the adhesion of EPCs impaired by TNF- $\alpha$ in vitro. The present study also aimed to determine whether RES affects the adhesion of late EPCs treated with TNF- $\alpha$. The results demonstrated that the adhesion potential of EPCs treated with TNF- $\alpha$ was significantly lower compared with the DMSO group (18.17 \pm 1.72 vs. $22.43 \pm 2.37$, respectively; $\mathrm{P}<0.05$; Fig. 3). However, the adhesion capacity of EPCs was 

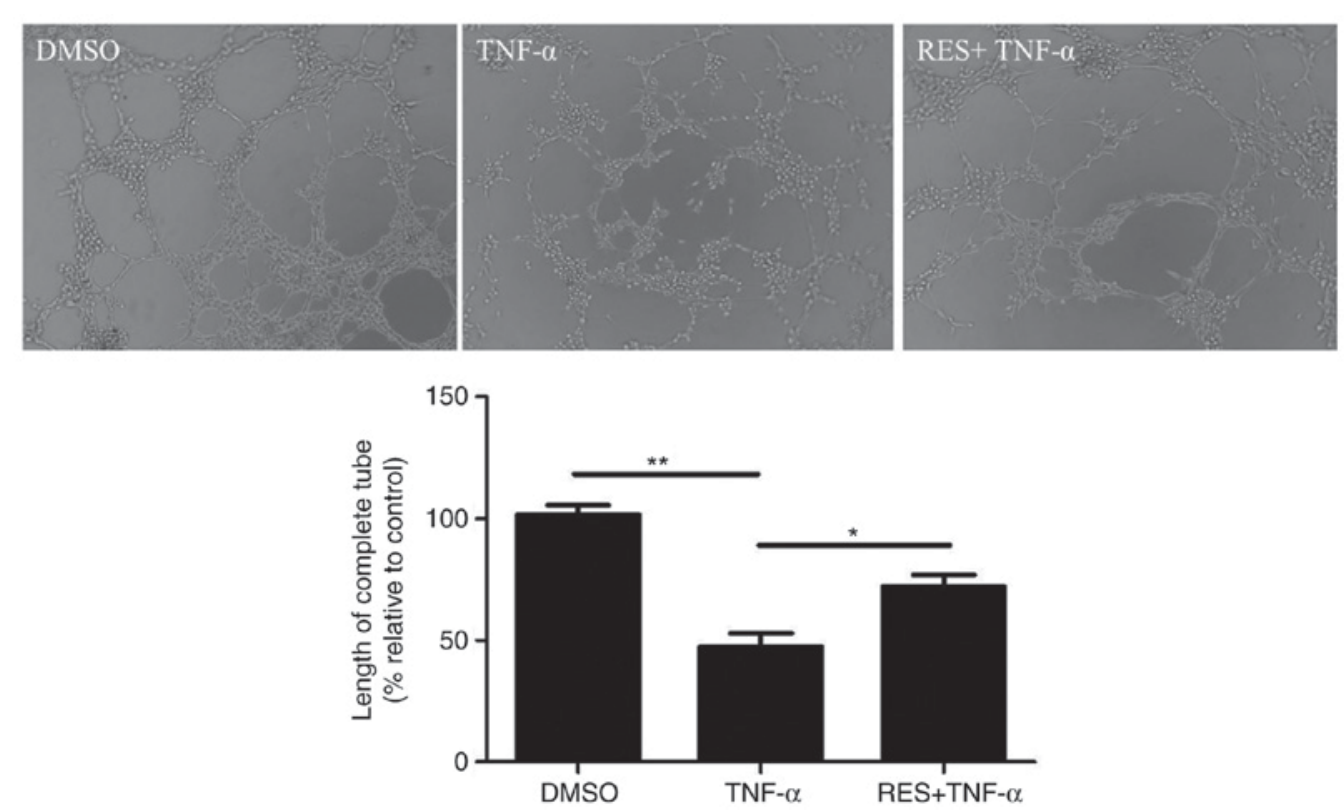

Figure 4. Effect of RES on the vasculogenesis of late EPCs that was inhibited by TNF- $\alpha$ in vitro. Enclosed networks of tubes are presented by light micrographs (magnification, x200). TNF- $\alpha$ inhibited the vasculogenesis of EPCs in vitro, while RES promoted vasculogenesis of EPCs in vitro. EPCs treated with DMSO served as the blank group. Data are presented as the mean + standard error of the mean, $\mathrm{n}=5$. ${ }^{*} \mathrm{P}<0.05$ and ${ }^{* *} \mathrm{P}<0.01$, as indicated. RES, resveratrol; EPCs, endothelial progenitor cells; TNF- $\alpha$, tumor necrosis factor- $\alpha$; DMSO, dimethyl sulfoxide.

markedly elevated in the group that was pre-exposed to RES (RES + TNF- $\alpha$ group) compared with the TNF- $\alpha$ only group (27.5 \pm 3.93 vs. $18.17 \pm 1.72$, respectively; $\mathrm{P}<0.01$; Fig. 3 ).

Effect of RES on the vasculogenesis of EPCs. The neovascularization capacity of EPCs was investigated using a vasculogenesis assay. TNF- $\alpha$ markedly inhibited the length of tubules by EPCs compared with the DMSO control $(\mathrm{P}<0.01 ;$ Fig. 4). By contrast, tubule length increased in response to pretreatment with RES compared with the treatment with TNF- $\alpha$ only $(\mathrm{P}<0.05$; Fig. 4).

Effect of RES on the levels of NO. NO secretion by EPCs was detected using a colorimetric assay kit in all three groups. NO secretion by EPCs was reduced in the TNF- $\alpha$ group compared with the DMSO group ( $\mathrm{P}<0.01$; Fig. 5). Conversely, a significant increase in NO production was observed in the RES + TNF- $\alpha$ group compared with the TNF- $\alpha$ group $(\mathrm{P}<0.05$; Fig. 5). Therefore, RES alleviated the TNF- $\alpha$-induced inhibition of NO release in EPCs.

Effect of RES on the expression of the inflammatory molecules ICAM-1 and MCP-1 in EPCs treated with TNF- $\alpha$. The mRNA levels of ICAM-1 and MCP-1 in the TNF- $\alpha$ group were significantly increased compared with the DMSO group $(\mathrm{P}<0.01$; Fig. 6). EPCs co-cultured with RES and TNF- $\alpha$ demonstrated markedly decreased mRNA expression of ICAM-1 (Fig. 6A) and MCP-1 (Fig. 6B) compared with the respective TNF- $\alpha$ groups $(\mathrm{P}<0.05)$. The above results indicated that RES may inhibit TNF- $\alpha$-induced increases in the expression of inflammatory molecules, including ICAM-1 and MCP-1, in late EPCs.

Effect of RES on KLF2 mRNA and protein expression in EPCs treated with TNF- $\alpha$. The mRNA levels of KLF2

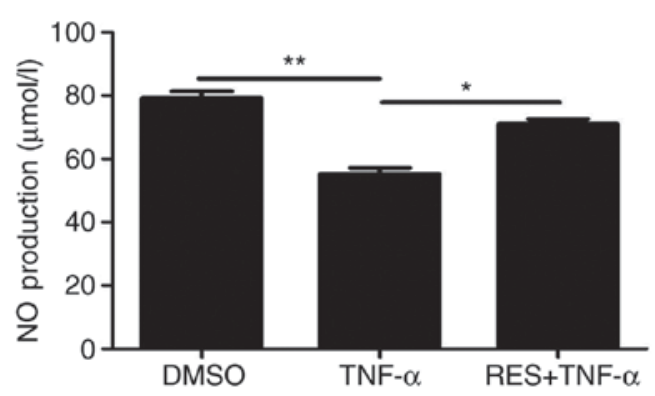

Figure 5. Effect of RES on the production of NO in late EPCs. NO production was detected by a colorimetric assay. $\mathrm{NO}$ production was inhibited by TNF- $\alpha$, while RES pretreatment enhanced NO levels compared with the TNF- $\alpha$ only group. EPCs treated with DMSO served as the blank group. Data are presented as the mean + standard error of the mean, $n=5$. ${ }^{*} \mathrm{P}<0.05$ and ${ }^{* *} \mathrm{P}<0.01$, as indicated. RES, resveratrol; NO, nitric oxide; EPCs, endothelial progenitor cells; TNF- $\alpha$, tumor necrosis factor- $\alpha$; DMSO, dimethyl sulfoxide.

were significantly reduced in late EPCs treated with TNF- $\alpha$ compared with EPCs treated with DMSO (P<0.01; Fig. 7A). However, KLF2 mRNA expression in the RES + TNF- $\alpha$ group was markedly enhanced compared with the TNF- $\alpha$ only group $(\mathrm{P}<0.05 ;$ Fig. 7A). Subsequently, the protein levels of KLF2 were determined in EPCs pretreated with RES at different concentrations $(5,10,20$ and $50 \mu \mathrm{mol} / \mathrm{l})$. The results demonstrated that TNF- $\alpha$ inhibited KLF2 protein expression (Fig. 7B). However, the protein levels of KLF2 were increased in a dose-dependent manner when EPCs were treated with RES at concentrations between 5 and $20 \mu \mathrm{mol} / 1$, and KLF2 protein expression was decreased in EPCs following treatment with $50 \mu \mathrm{mol} / 1$ RES compared with $20 \mu \mathrm{mol} / 1$ RES group (Fig. 7C). Therefore, these results indicated that $20 \mu \mathrm{mol} / 1$ RES was the optimal concentration to stimulate KLF2 protein expression in late EPCs. 



Figure 6. Effect of RES on the mRNA expression of ICAM-1 and MCP-1. The mRNA expression of (A) ICAM-1 and (B) MCP-1 was determined by reverse transcription-quantitative polymerase chain reaction. EPCs treated with DMSO served as the blank group. ${ }^{*} \mathrm{P}<0.05$ and ${ }^{* * *} \mathrm{P}<0.01$, as indicated. RES, resveratrol; ICAM-1, intercellular adhesion molecule-1; MCP-1, monocyte chemoattractant protein-1; DMSO, dimethyl sulfoxide; TNF- $\alpha$, tumor necrosis factor- $\alpha$.

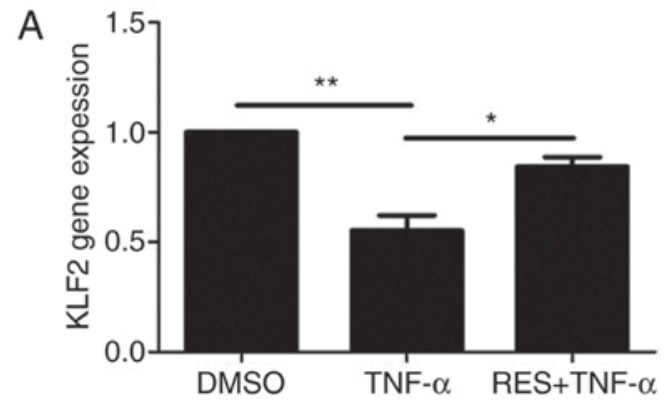

\section{B $\quad 50 R+T \quad 20 R+T \quad 10 R+T \quad 5 R+T \quad T N F-\alpha \quad$ DMSO}

$\mathrm{C}$

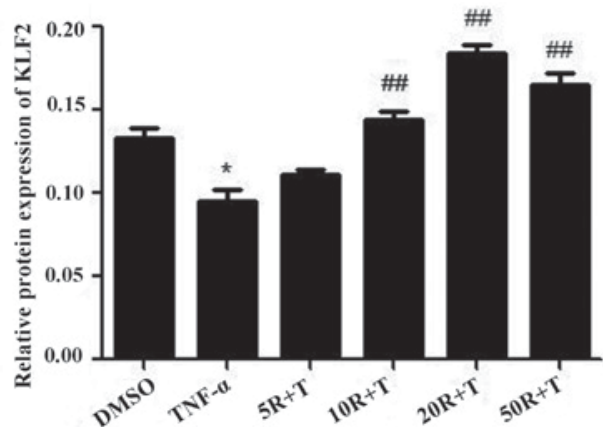

Figure 7. Effect of RES on KLF2 mRNA and protein expression in EPCs. (A) KLF2 mRNA expression was determined by reverse transcription-quantitative polymerase chain reaction. (B) KLF2 protein expression was determined by western blot analysis. For western blotting, EPCs were pretreated with RES at concentrations of 5, 10, 20 and $50 \mu \mathrm{mol} / 1$ for $12 \mathrm{~h}$, and subsequently, EPCs were cultured with $10 \mathrm{ng} / \mathrm{ml} \mathrm{TNF}-\alpha$ for $24 \mathrm{~h}$. $\beta$-actin was analyzed as a loading control. (C) Densitometric analysis for the western blot was performed by GelPro Analyser 4.0 software. EPCs treated with DMSO served as the blank group. ${ }^{*} \mathrm{P}<0.05$ and ${ }^{* *} \mathrm{P}<0.01$, as indicated. In $\mathrm{C},{ }^{*} \mathrm{P}<0.05$ vs. DMSO groups, ${ }^{\# \#} \mathrm{P}<0.01$ vs. TNF- $\alpha$ groups. RES, resveratrol; KLF2, Krüppel-like factor-2; EPCs, endothelial progenitor cells; DMSO, dimethyl sulfoxide; TNF- $\alpha$, tumor necrosis factor- $\alpha$; R, resveratrol; T, tumor necrosis factor- $\alpha$.

\section{Discussion}

EPCs can promote plaque angiogenesis and restore endothelial function to serve a protective role in atherosclerotic disease (23). The biological properties of EPCs have clinical implications for coronary atherosclerotic disease, since cardiovascular risk factors can negatively influence the number and function of EPCs $(23,24)$. A number of studies have demonstrated that RES delayed the senescence of EPCs by augmenting telomerase activity to maintain the appropriate levels and function of EPCs (25-27). The present study aimed to determine the effect of RES on the function of EPCs treated with TNF- $\alpha$ and the underlying anti-inflammatory mechanisms, in addition to the potentially protective role of RES in atherosclerotic disease.
In the current study, the effects of RES on the proliferation, migration, adhesion, tube formation ability and NO production of EPCs were evaluated following treatment with TNF- $\alpha$. The results demonstrated that RES attenuated TNF- $\alpha$-induced damage to the functioning of EPCs. These results are consistent with a previous study by Wang et al (28), which demonstrated that RES may promote the proliferation, adhesion and migration of EPCs in a dose- and time-dependent manner. The aforementioned study also indicated that RES increased the expression of vascular endothelial growth factor to further induce vasculogenesis (28).

The results of the present study indicated that RES promoted NO production and KLF2 expression in EPCs, and it has been previously reported that endothelial NO release 
may protect cells against AS (29). NO is synthesized by inducible nitric oxide synthase and eNOS, where eNOS acts as an anti-atherosclerotic factor (30). It has been previously demonstrated that RES increased the expression of eNOS in endothelial cells in vitro $(31,32)$, which was mediated by the activation of sirtuin 1 (SIRT1) and subsequent activation of the transcription factor KLF2 (33). The KLF2-dependent signaling pathway has been reported to enhance the enzymatic activity of dimethylarginine dimethylaminohydrolase II, which leads to the degradation of asymmetric dimethylarginine, an endogenous inhibitor of eNOS $(9,34)$. Therefore, we hypothesized that RES may increase NO production in EPCs via upregulation of KLF2.

Piga et al (35) indicated that adhesion and migration of human aortic endothelial cells were influenced by overexpression of ICAM-1 and MCP-1. In addition, upregulation of ICAM-1 and MCP-1 was considered a marker for AS progression via TNF- $\alpha$-induced activation of the nuclear factor- $\kappa \mathrm{B}(\mathrm{NF}-\kappa \mathrm{B})$ pathway (36). Therefore, in the present study, the expression of ICAM-1 and MCP-1 was detected in EPCs following inflammatory damage induced by TNF- $\alpha$. Based on the results of the present study, it may be hypothesized that TNF- $\alpha$ may promote the expression of ICAM-1 and MCP-1 in EPCs, which may be responsible for alterations in the function of EPCs during the development of AS. Furthermore, the present study demonstrated that RES may attenuate inflammatory damage of EPCs via downregulation of ICAM-1 and MCP-1. Similar to the results of the present study, Zhu et al (37) demonstrated that RES may reduce TNF- $\alpha$-activated expression of MCP-1 via inhibition of NF- $\kappa \mathrm{B}$ transcriptional activity in adipocytes. Xiao et al (38) indicated that RES inhibited the expression of TNF- $\alpha$-activated ICAM-1 and vascular cell adhesion molecule-1 (VCAM-1) in endothelial cells. Additionally, several studies have indicated that KLF2 may inhibit inflammation via suppression of a number of adhesion molecules, including VCAM-1, E-selectin and MCP-1 $(39,40)$. Therefore, we hypothesized that RES may downregulate the expression of ICAM-1 and MCP-1 in response to proinflammatory stimuli by increasing the expression of KLF2.

KLF2 has been reported to be involved in the prevention of the progression of AS via anti-inflammatory action and the regulation of eNOS expression $(41,42)$. Based on the results of the present study and previous reports, we hypothesized that RES may have potential in the development of novel therapies against AS, and the anti-atherosclerotic effects of RES may be attributed to the promotion of KLF2 expression and subsequent inhibition of inflammation and promotion of NO release.

In conclusion, the results of the present study demonstrated that RES increased the proliferation, migration, adhesion, tube formation ability and NO release of EPCs and upregulated KLF2 expression following treatment with TNF- $\alpha$, and also inhibited the TNF- $\alpha$-stimulated expression of ICAM-1 and MCP-1. Therefore, these results indicate that RES may alter the growth properties of EPCs treated with TNF- $\alpha$ by increasing $\mathrm{NO}$ production and ameliorating inflammatory damage by reducing the expression levels of inflammatory molecules, including ICAM-1 and MCP-1, through regulation of KLF2-associated signaling pathways.

\section{Acknowledgements}

Not applicable.

\section{Funding}

The present study was supported by the National Natural Science Foundation of China (grant nos. 31570941, 31270993 and 81700406), the Program for New Century Excellent Talents in University (grant no. NCET-10-0922), the Natural Science Foundation of Shandong Province (grant nos. ZR2013CQ032 and ZR2014JL018, ZR2016CM20), Administration of Traditional Chinese Medicine of Shandong Province (grants no. 2016WS0667 and 2015-239) and Shandong Province Higher Educational Science and Technology Program (grants no. J14LK59, J14LK12 and J15LK08).

\section{Availability of data and materials}

The analyzed data sets generated during the study are available from the corresponding author on reasonable request.

\section{Authors' contributions}

HC, HL and MC: Conception and design of the research. XG, HY, XZ, XC and XL: Acquisition of data, analysis and interpretation of data and statistical analysis. HC and HL: Drafting the manuscript. MC: Revision of manuscript for important intellectual content.

\section{Ethics approval and consent to participate}

The present study was approved by the Medical Ethics Committee of Weifang Medical University (Weifang, China) and was performed in accordance with the committee guidelines.

\section{Consent for publication}

Not applicable.

\section{Competing interests}

The authors declare that they have no competing interests.

\section{References}

1. Hill JM, Zalos G, Halcox JP, Schenke WH, Waclawiw MA, Quyyumi AA and Finkel T: Circulating endothelial progenitor cells, vascular function, and cardiovascular risk. N Engl J Med 348: 593-600, 2003.

2. Schmidt-Lucke C, Rössig L, Fichtlscherer S, Vasa M, Britten M, Kämper U, Dimmeler S and Zeiher AM: Reduced number of circulating endothelial progenitor cells predicts future cardiovascular events: Proof of concept for the clinical importance of endogenous vascular repair. Circulation 111: 2981-2987, 2005.

3. Zampetaki A, Kirton JP and Xu Q: Vascular repair by endothelial progenitor cells. Cardiovasc Res 78: 413-421, 2008.

4. Miller-Kasprzak E and Jagodziński PP: Endothelial progenitor cells as a new agent contributing to vascular repair. Arch Immunol Ther Exp (Warsz) 55: 247-259, 2007.

5. Paramo JA, Rodríguez JA and Orbe J: Atherosclerosis in inflammatory diseases. Med Clin (Barc) 128: 749-756, 2007 (In Spanish). 
6. Tousoulis D, Andreou I, Antoniades C, Tentolouris C and Stefanadis C: Role of inflammation and oxidative stress in endothelial progenitor cell function and mobilization: Therapeutic implications for cardiovascular diseases. Atherosclerosis 201: 236-247, 2008

7. Jang M,Cai L, Udeani GO, Slowing KV, Thomas CF, Beecher CW, Fong HH, Farnsworth NR, Kinghorn AD, Mehta RG, et al: Cancer chemopreventive activity of resveratrol, a natural product derived from grapes. Science 275: 218-220, 1997.

8. Baur JA and Sinclair DA: Therapeutic potential of resveratrol: The in vivo evidence. Nat Rev Drug Discov 5: 493-506, 2006.

9. Schmitt CA, Heiss EH and Dirsch VM: Effect of resveratrol on endothelial cell function: Molecular mechanisms. Biofactors 36: 342-349, 2010

10. Wang H, Yang YJ, Qian HY, Zhang Q, Xu H and Li JJ: Resveratrol in cardiovascular disease: What is known from current research? Heart Fail Rev 17: 437-448, 2012.

11. Bruunsgaard H, Skinhøj P, Pedersen AN, Schroll M and Pedersen BK: Ageing, tumour necrosis factor-alpha (TNF-alpha) and atherosclerosis. Clin Exp Immunol 121: 255-260, 2000

12. Zhang H, Zhang J, Ungvari Z and Zhang C: Resveratrol improves endothelial function: Role of TNF \{alpha\} and vascular oxidative stress. Arterioscler Thromb Vasc Biol 29: 1164-1171, 2009.

13. Pearson R, Fleetwood J, Eaton S, Crossley M and Bao S: Krüppel-like transcription factors: A functional family. Int $J$ Biochem Cell Biol 40: 1996-2001, 2008.

14. Lin Z, Kumar A, SenBanerjee S, Staniszewski K, Parmar K, Vaughan DE, Gimbrone MA Jr, Balasubramanian V, García-Cardeña G and Jain MK: Kruppel-like factor 2 (KLF2) regulates endothelial thrombotic function. Circ Res 96: e48-e57, 2005.

15. Wu J, Bohanan CS, Neumann JC and Lingrel JB: KLF2 transcription factor modulates blood vessel maturation through smooth muscle cell migration. J Biol Chem 283: 3942-3950, 2008.

16. Sebzda E, Zou Z, Lee JS, Wang T and Kahn ML: Transcription factor KLF2 regulates the migration of naive T cells by restricting chemokine receptor expression patterns. Nat Immunol 9: 292-300, 2008

17. Dekker RJ, van Thienen JV, Rohlena J, de Jager SC, Elderkamp YW, Seppen J, de Vries CJ, Biessen EA, van Berkel TJ, Pannekoek H and Horrevoets AJ: Endothelial KLF2 links local arterial shear stress levels to the expression of vascular tone-regulating genes. Am J Pathol 167: 609-618, 2005.

18. Kumar A, Lin Z, SenBanerjee S and Jain MK: Tumor necrosis factor alpha-mediated reduction of KLF2 is due to inhibition of MEF2 by NF-kappaB and histone deacetylases. Mol Cell Biol 25: 5893-5903, 2005

19. Li H, Zhang X, Guan X, Cui X, Wang Y, Chu H and Cheng M: Advanced glycation end products impair the migration, adhesion and secretion potentials of late endothelial progenitor cells Cardiovasc Diabetol 11: 46, 2012

20. Chen YH, Lin SJ, Lin FY, Wu TC, Tsao CR, Huang PH, Liu PL, Chen YL and Chen JW: High glucose impairs early and late endothelial progenitor cells by modifying nitric oxide-related but not oxidative stress-mediated mechanisms. Diabetes 56 $1559-1568,2007$

21. Liang C, YR HT, He Z, Jiang Q, Wu J, Zhen Y, Fan M and Wu Z: Rosiglitazone via upregulation of Akt/eNOS pathways attenuates dysfunction of endothelial progenitor cells, induced by advanced glycation end products. Br J Pharmacol 158: 1865-1873, 2009.

22. Livak KJ and Schmittgen TD: Analysis of relative gene expression data using real-time quantitative PCR and the 2(-Delta Delta C(T)) method. methods 25: 402-408, 2001.

23. Werner $\mathrm{N}$ and Nickenig G: Clinical and therapeutical implications of EPC biology in atherosclerosis. J Cell Mol Med 10: 318-332, 2006.

24. Ku IA, Imboden JB, Hsue PY and Ganz P: Rheumatoid arthritis: Model of systemic inflammation driving atherosclerosis. Circ J 73: 977-985, 2009

25. Xia L, Wang XX, Hu XS, Guo XG, Shang YP, Chen HJ, Zeng CL, Zhang FR and Chen JZ: Resveratrol reduces endothelial progenitor cells senescence through augmentation of telomerase activity by Akt-dependent mechanisms. Br J Pharmacol 155: 387-394, 2008.
26. Gu J, Wang CQ, Zhang DD, Fan HH, He B, Wang BY and Huang DJ: Effect of resveratrol on reendothelialization and neointimal formation in intimal injury model. Chin J Arterioscler 14: 829-834, 2006

27. Wang XB, Zhu L, Huang J, Yin YG, Kong XQ, Rong QF, Shi AW and Cao KJ: Resveratrol-induced augmentation of telomerase activity delays senescence of endothelial progenitor cells. Chin Med J (Engl) 124: 4310-4315, 2011.

28. Wang XB, Huang J, Zou JG, Su EB, Shan QJ, Yang ZJ and Cao KJ: Effects of resveratrol on number and activity of endothelial progenitor cells from human peripheral blood. Clin Exp Pharmacol Physiol 34: 1109-1115, 2007.

29. Matthys KE and Bult H: Nitric oxide function in atherosclerosis. Mediators Inflamm 6: 3-21, 1997.

30. Leifeld L, Fielenbach M, Dumoulin FL, Speidel N, Sauerbruch T and Spengler U: Inducible nitric oxide synthase (iNOS) and endothelial nitric oxide synthase (eNOS) expression in fulminant hepatic failure. J Hepatol 37: 613-619, 2002.

31. Klinge CM, Blankenship KA, Risinger KE, Bhatnagar S, Noisin EL, Sumanasekera WK, Zhao L, Brey DM and Keynton RS: Resveratrol and estradiol rapidly activate MAPK signaling through estrogen receptors alpha and beta in endothelial cells. J Biol Chem 280: 7460-7468, 2005.

32. Wallerath T, Deckert G, Ternes T, Anderson H, Li H, Witte $\mathrm{K}$ and Förstermann U: Resveratrol, a polyphenolic phytoalexin present in red wine, enhances expression and activity of endothelial nitric oxide synthase. Circulation 106: 1652-1658, 2002.

33. Gracia-Sancho J, Villarreal G Jr,Zhang Y and García-Cardeña G: Activation of SIRT1 by resveratrol induces KLF2 expression conferring an endothelial vasoprotective phenotypee. Cardiovasc Res 85: 514-519, 2010.

34. Scalera F, Fulge B, Martens-Lobenhoffer J, Heimburg A and Bode-Böger SM: Red wine decreases asymmetric dimethylarginine via SIRT1 induction in human endothelial cells. Biochem Biophys Res Commun 390: 703-709, 2009.

35. Piga R, Naito Y, Kokura S, Handa O and Yoshikawa T: Short-term high glucose exposure induces monocyte-endothelial cells adhesion and transmigration by increasing VCAM-1 and MCP-1 expression in human aortic endothelial cells. Atherosclerosis 193: 328-334, 2007.

36. Wang Y, Zhao X, Wang YS, Song SL, Liang H and Ji AG: An extract from medical leech improve the function of endothelial cells in vitro and attenuates atherosclerosis in ApoE null mice by reducing macrophages in the lesions. Biochem Biophys Res Commun 455: 119-125, 2014

37. Zhu J, Yong W, Wu X, Yu Y, Lv J, Liu C, Mao X, Zhu Y, Xu K, Han X and Liu C: Anti-inflammatory effect of resveratrol on TNF-alpha-induced MCP-1 expression in adipocytes. Biochem Biophys Res Commun 369: 471-477, 2008.

38. Xiao J, Song J, Hodara V, Ford A, Wang XL, Shi Q, Chen L and Vandeberg JL: Protective effects of resveratrol on TNF- $\alpha$-induced endothelial cytotoxicity in baboon femoral arterial endothelial cells. J Diabetes Res 2013, 2013. doi: 10.1155/2013/185172.

39. Senbanerjee S, Lin Z, Atkins GB, Greif DM, Rao RM, Kumar A, Feinberg MW, Chen Z, Simon DI, Luscinskas FW, et al: KLF2 is a novel transcriptional regulator of endothelial proinflammatory activation. J Exp Med 199: 1305-1315, 2004.

40. Hampole AV, Mahabeleshwar GH, Sharma N and Jain MK: Abstract 5546: Kruppel-like factor 2(KLF)2 inhibits macrophage pro-inflammatory activation. Circulation 120: S1113-S1114, 2009.

41. Zhou XB and Yang LX: Krüppel-like factor 2 and atherosclerosis. Adv Cardiovasc Dis 33: 224-246, 2012 (In Chinese).

42. Jia YJ and Li JJ: Research Progress of KLF2 anti-atherosclerosis. Mol Cardiol China 5: 303-307, 2012 (In Chinese).

This work is licensed under a Creative Commons Attribution-NonCommercial-NoDerivatives 4.0 International (CC BY-NC-ND 4.0) License. 